\title{
Photorefractive keratectomy for moderate myopia with the VISX and Summit excimer lasers: A retrospective study
}

\author{
Ceratectomia fotorrefrativa para correção de miopia moderada com excimer lasers \\ VISX e Summit: Estudo retrospectivo
}

João C. Ribeiro ${ }^{(1,2)}$

Jean M. Ancel ${ }^{(3)}$

Marguerite B. McDonald (4)

Ray J. Varnell (5)

\section{SUMMARY}

Purpose: To present photorefractive keratectomy (PRK) results for myopia ranging from $-4,00$ to $-6,00$ diopters performed with the VISX and Summit excimer lasers.

Methods: To be eligible for this study, patients had to be 20 to 45 years of age, have $\mathbf{- 4 . 0 0}$ to $\mathbf{- 6 . 0 0}$ diopters of myopia and have no more than $1 \mathrm{D}$ of astigmatism. The Summit group was composed of 51 eyes. The baseline preoperative spherical equivalent of myopia was $\mathbf{- 5 . 2 2} \pm$ 0.17 and surgeries were performed with the Excimed UV 200 LA Excimer Laser. In the VISX group, there were 53 eyes and the baseline refractive error was $-4.85 \pm 0.16$ and surgeries were performed with the Twenty/Twenty Excimer Laser.

Results: At six-month examination, haze ranged from 0 to 1 $(M: 0.56 \pm 0.07)$ in the VISX group and from 0 to $3(M: 0.58 \pm 0.08)$ in the Summit group. Uncorrected vision at six months was 20/20 or better in $22 \%$ of eyes and $20 / 40$ or better in $83 \%$ of eyes in the VISX group. In the Summit group, $25 \%$ of eyes were $20 / 20$ or better and $\mathbf{7 1 \%}$ were $20 / 40$ or better at the six-month examination.

Conclusion: It is reassuring that PRK of patients with $\mathbf{- 4 . 0 0}$ to $-6.00 \mathrm{D}$ of myopia results in acceptable results.

Keywords: Excimer laser; Myopia; Correction.

\section{INTRODUCTION}

Since the introduction of the $193 \mathrm{~nm}$ argon-fluoride excimer laser for cornea surgery in $1983^{1}$, much progress has been made in the use of this pulsed gas laser to treat myopia. Currently, photorefractive keratectomy (PRK) and laser assisted in situ keratomileusis (LASIK) are the two primary procedures used for the correction of myopia. PRK has become a common technique worldwide for the treatment of low to moderate myopia but recently it has been suggested that LASIK may be a procedure preferred to PRK for higher degrees of myopia ${ }^{2}$.

Seiler et $\mathrm{al}^{3}$ reported that after a single PRK treatment for myopias up to $-3,0$ diopters, $100 \%$ of eyes were within 1,0 diopter of emmetropia and $97 \%$ of eyes had an uncorrected visual acuity of $20 / 40$ or better. For higher degrees of myopia, PRK results are said to be less predictable and stable.

The purpose of this study is to evaluate the efficacy of PRK, in the treatment of myopia ranging from -4.00 to -6.00 diopters with the VISX and Summit excimer lasers. 


\section{PATIENTS AND METHODS}

To be eligible for this study, patients had to be 20 to 45 years of age, have -4.00 to -6.00 diopters of myopia, have best spectacle-corrected visual acuity of 20/40 or better in both eyes, and have no more than $1 \mathrm{D}$ of astigmatism. Other criteria included no active or residual diseases that were likely to affect wound healing such as keloids or excessive dermal scarring. Patients wearing soft contact lenses or rigid gas permeable contact lenses were required to discontinue lenses 2 weeks before baseline evaluation and patients wearing polymethylmethacrylate (PMMA) hard contact lenses were required to discontinue wearing them 3 weeks before baseline evaluation and to demonstrate regular keratometry mires and less than 0.50 diopters of variation in both meridians on manifest refraction during at least two of three weekly visits thereafter.

The Summit group was composed of 51 eyes. The baseline preoperative spherical equivalent of myopia ranged from -4.00 to -6.00 diopters (M:-5.22 \pm 0.17 ). There were 23 males and 28 females. Ages ranged from 21 to 42 years (M:30.94 \pm 0.86 ). Surgeries were performed at the Hospital A. Paré, Paris, with the Excimed UV 200 LA Excimer Laser (Summit Technology, Waltham, Massachusetts). The wavelength of the argonfluoride laser was $193 \mathrm{~nm}$, the fluence $180 \mathrm{~mJ} / \mathrm{cm}^{2}$, and the pulse repetition rate $10 \mathrm{~Hz}$. Ablation zone ranged from 3.7 to $5.0 \mathrm{~mm}$. At the beginning of each treatment session a homogeneity test was carried out to monitor beam quality. The surgical procedure is described elsewhere ${ }^{4}$.

In the VISX group, there were 53 eyes and the baseline refractive error ranged from -4.00 to -6.00 diopters (M:-4.85 $\pm 0.16)$. Ages ranged from 20 to 44 years $(\mathrm{M}: 33.13 \pm 1.00)$ and there were 42 males and 11 females. Surgeries were performed at the Louisiana State University Eye Center, New Orleans, with the Twenty/Twenty Excimer Laser (VISX Inc., Santa Clara, California), as previously described ${ }^{5}$. The wavelength was $193 \mathrm{~nm}$, fluence 160 to $168 \mathrm{~mJ} / \mathrm{cm}^{2}$, repetition rate of $5 \mathrm{~Hz}$ and ablation zone 5.00 to $6.00 \mathrm{~mm}$ in diameter.

Preoperative examinations included measurement of uncorrected and best corrected visual acuity, manifest refraction, pachymetry, keratometry, intraocular pressure measurement, grading of corneal clarity and mapping of corneal topography.

Visual acuity data originally recorded in Snellen notation were converted to minutes of visual angle, and logarithms of the minutes of visual angles were used for statistical analysis ${ }^{6}$.

Attempted correction was the spherical equivalent at the corneal plane for that eye. Corneal haze was graded at each examination according to the following scale: 0 indicated clear, no haze; 0.5 indicated barely detectable haze; 1 indicated mild haze not affecting refraction; 1.5 indicated haze mildly affecting refraction; 2 indicated moderate haze with refraction possible but difficult; 3 indicated opacity preventing refraction but anterior chamber easily viewed and 4 indicated opacity impairing view of anterior chamber. Topographic analysis was performed to evaluate the ablation with the EyeSys Corneal Analysis System (EyeSys Laboratories, Houston, TX) in the Summit group and with TMS-1 (TomeyComputed Anatomy, Tomey Technology Inc., Cambridge, MA) in the VISX group.

In the VISX group, immediately after laser surgery, one drop of $1 \%$ atropine sulfate was applied. Afterwards, $0.3 \%$ ciprofloxacin. $\mathrm{HCl} 0.3 \%$ drops 4 times a day and $0.1 \%$ diclofenac sodium drops 4 times a day were applied and a therapeutic contact lens placed on the eye. Treated eyes were examined for infection every 24 to 48 hours until reepithelialization was completed. Therafter, only topical fluorometholone drops were administered at a tapering dosage for 5 months, as follows: 4 times a day for 1 month, 3 times a day for the second month, twice a day for the third month, once a day for the fourth month, and once every other day for the fifth month. Postoperative examinations, which consisted of the same tests and measurement as the preoperative examinations, were performed at 1-, 3- and 6- month visits.

The Summit group received no medication immediately after laser surgery and all eyes were patched till the second postoperative day. According to the reepithelialization rate, corticotherapy and antibiotic therapy (dexamethasone-neomycin-polymyxin drops 5 times a day) were started on the second postoperative day or delayed one or two days. Thereafter, it was tapered for the next 5 months. The postoperative examinations were the same as for the VISX group.

Data variable was analyzed with SAS-PC software, using the procedure for general linear models with the Ismeans options for multicomparison evaluations.

\section{RESULTS}

The procedure was completed successfully in all patients. The epithelial defect was closed after 5 days in all eyes. There were no ophthalmic complications during the six-month follow-up.

Corneal Clarity: All eyes were graded as clear prior to the surgery. At one-month examination, haze ranged from 0 to 1.5 (M:0.7 \pm 0.07$)$ in the VISX group and from 1 to $2(\mathrm{M}: 1.2 \pm$ $0.07)$ in the Summit group. After 6 months, these values ranged from 0 to 1 (M:0.56 \pm 0.07 ) and from 0 to 3 (M:0.58 \pm 0.08 ) respectively. Figure 1 shows mean corneal clarity scores plotted over time for both groups.

Visual Acuity: Mean uncorrected visual acuity was FC (range: $20 / 200$ to FC) preoperatively and improved to $20 / 50$ (range: $20 / 20$ to FC) by month 1 and to $20 / 40$ (range: $20 / 20$ to20/200) by month 6 in the VISX group. In the Summit group, mean uncorrected visual acuity was not determined prior to surgery or at one-month examination. At 6 months, uncorrected visual acuity was 20/40 (range: $20 / 20$ to $20 / 200$ ). Uncorrected visual acuity at six months was $20 / 20$ or better in 
$22 \%$ of eyes and $20 / 40$ or better in $83 \%$ of eyes in the VISX group. In the Summit group, $25 \%$ of eyes were $20 / 20$ or better and $71 \%$ were $20 / 40$ or better at 6 -month examination. The evolution of uncorrected visual acuity over time for both groups is shown in Figure 2.

Best spectacle-corrected visual acuity: In the VISX group it was $20 / 20$ (range: $20 / 15$ to $20 / 25$ ) preoperatively, 20/25 (range: $20 / 15$ to $20 / 60$ ) at month one, and $20 / 20$ (range: $20 / 15$ to $20 / 40$ ) at month 6 . In the Summit group, it was 20/20 (range: 20/20 to20/30) preoperatively, undetermined at month one, and 20/20 (range: 20/20 to 20/30) at month 6 . In the VISX group, $22.2 \%$ of patients lost one line and $13.8 \%$ lost two lines of best corrected visual acuity; in the Summit group $22.8 \%$ lost one line and 5.7\% lost two lines. No patient in either group lost more than 2 lines of

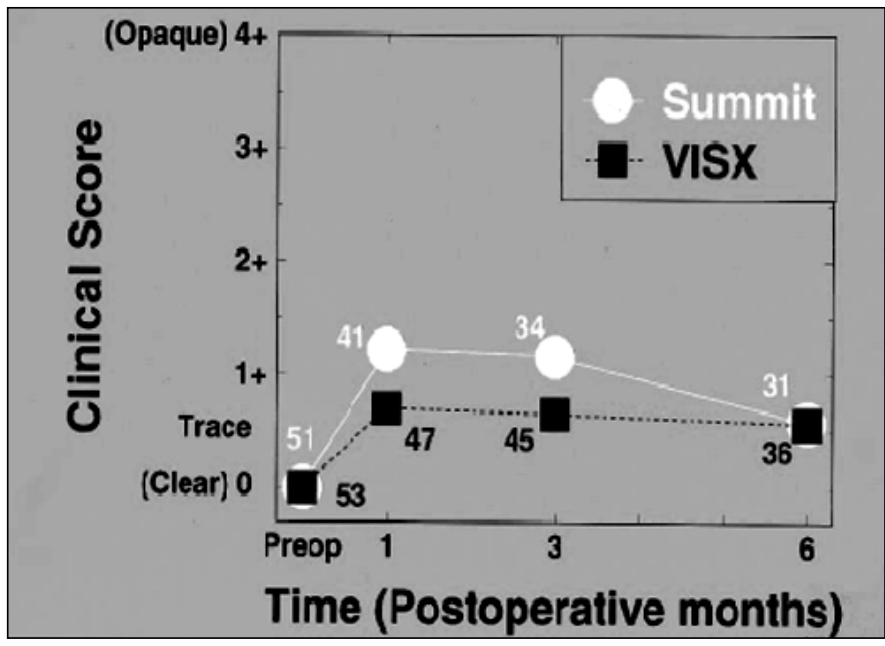

Figure 1 - Corneal haze after PRK with the VISX and Summit excimer lasers.

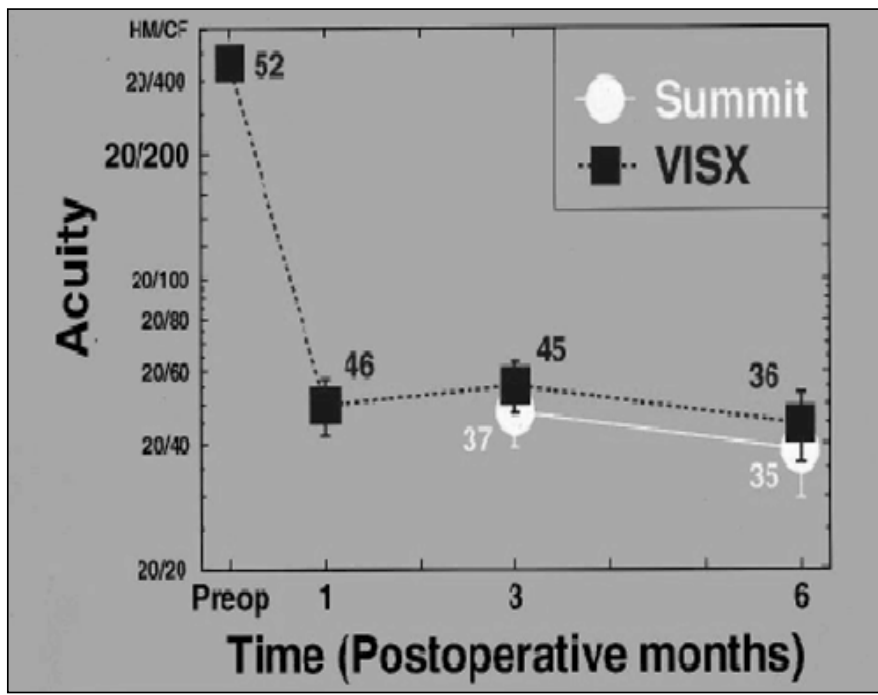

Figure 2 - Uncorrected visual acuity after PRK with the VISX and Summit excimer lasers. best-corrected visual acuity. Figure 3 shows the evolution of best spectacle-corrected acuity plotted over time for both groups.

Refraction: Average spherical equivalent (SE) changed from $-4.85 \pm 0.16 \mathrm{D}$ preoperatively to $+0.71 \pm 0.17 \mathrm{D}$ (range: -1.63 to +4.63$) 1$ month after surgery and to $-0.62 \pm 0.20 \mathrm{D}$ (range: -4.00 to +2.00 ) by month 6 in the VISX group. The Summit group had a mean SE of $-5.22 \pm 0.17 \mathrm{D}$ before the surgery. At 1 month, average $\mathrm{SE}$ was $+0.80 \pm 0.17 \mathrm{D}$ (range: -1.23 to +3.38 ), and at 6 month, it was $-0.49 \pm 0.20 \mathrm{D}$ (range: -3.36 to +2.58 ). At 6 -month examination, $61.2 \%$ of eyes in the VISX group and $65.7 \%$ of eyes in the Summit group were $\pm 1 \mathrm{D}$ of emmetropia and $94.5 \%$ and $85.7 \%$ were $\pm 2 \mathrm{D}$ of emmetropia respectively. Figure 4 shows mean SE over time for both groups.

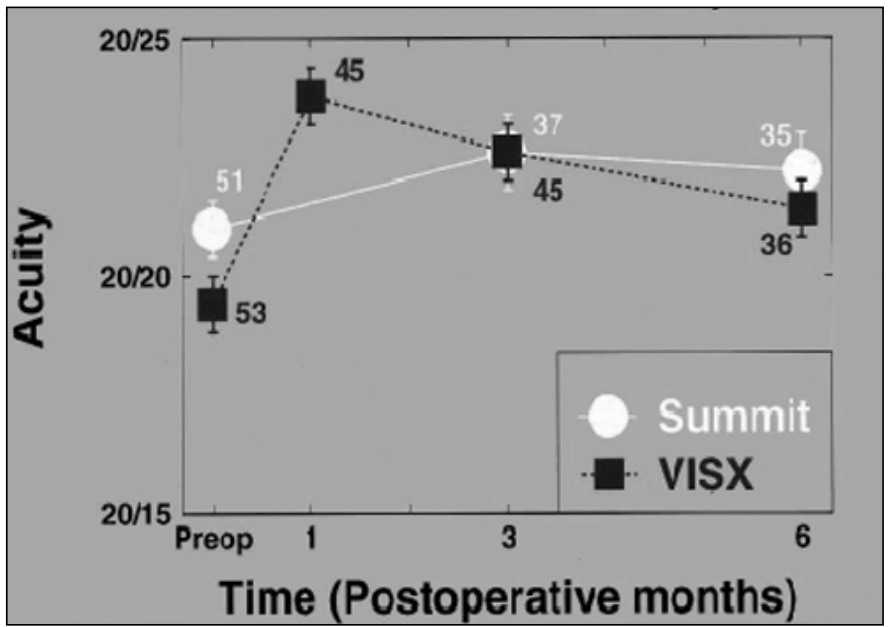

Figure 3 - Best corrected visual acuity after PRK with the VISX and Summit excimer lasers.

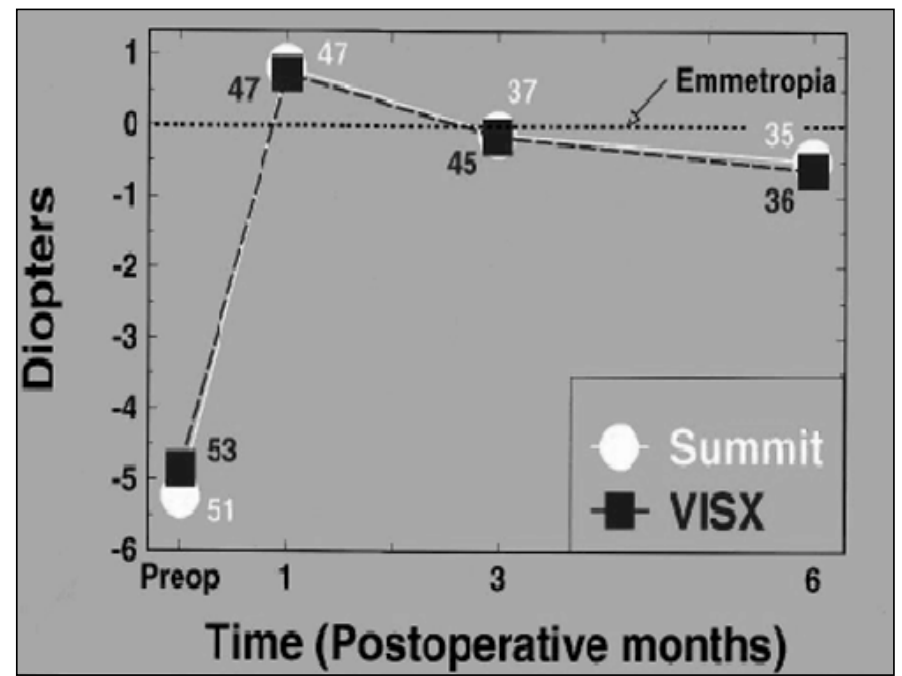

Figure 4 - Evolution of the spherical equivalent after PRK with the VISX and Summit excimer lasers. 
Complications: There were no complications in both groups during the follow-up period.

There were no significant differences in clinical results between lasers.

\section{DISCUSSION}

The main motivation of patients undergoing refractive surgery is to decrease their dependence on contact lenses or spectacles. After a single PRK treatment for myopia ranging from $-1,5$ to $-6,0$ diopters, $85 \%$ and $90,7 \%$ of eyes had a visual acuity of 20/40 or better with the VISX and Summit excimer lasers respectively ${ }^{7,8}$.

Photorefractive keratectomy appears to be less effective for moderate to high myopia. This technique presents a trend towards a loss of best spectacle-corrected visual acuity due to loss of corneal clarity and corneal topography irregularity, and a tendency to regression that renders the final visual outcome less predictable ${ }^{9,10}$.

In this double-center, retrospective study, there were no significant differences in clinical results between lasers. For both lasers at six months, haze averaged trace, uncorrected vision averaged $20 / 40$, best corrected vision averaged $20 / 20$, and spherical equivalents averaged approximately $-0.50 \mathrm{D}$. In both groups of eyes, approximately $75 \%$ saw $20 / 40$ or better uncorrected, $20 \%$ lost one line of best corrected acuity while none lost more than two lines, and $60 \%$ were within $\pm 1 \mathrm{D}$ of emmetropia.

Many of these surgeries were performed with smaller ablation zones, which are believed to cause greater regression and corneal haze. Larger ablation zones appear less likely to stimulate an aggressive wound healing response, thus resulting in improved predictability of PRK ${ }^{11}$.

Despite a more rapid improvement in uncorrected visual acuity and less discomfort with LASIK, Hersh et al. ${ }^{2}$ found similar outcomes between this procedure and PRK for the correction of 9.2 diopters of myopia. Photorefractive keratectomy has the advantage of greater ease of surgery without complications associated with a corneal flap. For higher degrees of myopia, Pallikaris and Siganos ${ }^{12}$ found LASIK to be more predictable and stable than PRK.

The present data have limitations including limited followup (although 6 months may be an adequate period of time to achieve refractive stability after PRK, refractive changes may continue after this period) and steroid regimen after PRK (steroid therapy after surgery was left to the individual surgeons).

In this study however, because one laser was used in France and the other used in the United States, the differences between lasers are confounded with differences between patient populations, surgeons, treatment strategies, and postoperative care. The lasers used in this study were first generation lasers. How much these factors contribute to the results obtained here is unknown.
Nevertheless, it is reassuring that PRK of patients with -4.00 to $-6.00 \mathrm{D}$ of myopia results in acceptable results, despite the fact that patients may be from different cultures, treated with different lasers operated by different surgeons using different strategies.

\section{RESUMO}

Objetivo: Apresentar os resultados obtidos com ceratectomia fotorrefrativa (PRK) para a correção de miopia variando de -4,0 a -6,0 dioptrias realizadas com os excimer lasers VISX e Summit.

Métodos: Para o estudo foram avaliados os resultados de $P R K$ realizadas em pacientes com idade entre 20 e 45 anos, miopia entre -4,0 e -6,0 dioptrias e astigmatismo até 1,0 dioptria. O grupo operado com o laser da marca Summit era composto de 51 olhos. O equivalente esférico médio préoperatório era de -5,22 $\pm 0,17$ dioptrias e as cirurgias foram realizadas com o Excimed UV 200 LA Excimer Laser. O grupo operado com o laser VISX, era composto de 53 olhos e o erro refrativo preoperatório era de $-4,85 \pm 0,16$ dioptrias e as cirurgias foram realizadas com o Twenty/Twenty Excimer Laser.

Resultados: Exame seis meses após a cirurgia revelou "haze" variando de 0 a $1(M: 0,56 \pm 0,07)$ no grupo VISX e variando de 0 a 3 (M:0,58 $\pm 0,08)$ no grupo Summit. Neste mesmo exame, acuidade visual sem correção era de 20/20 ou melhor em $22 \%$ dos olhos e 20/40 ou melhor em $83 \%$ dos olhos no grupo VISX. No grupo Summit, $25 \%$ dos olhos tinham visão melhor ou igual a 20/20 e 71\% melhor ou igual a 20/40.

Conclusão: Ceratectomia fotorrefrativa realizadas em olhos com miopia variando de $-4,0$ a -6,0 dioptrias apresenta resultados aceitáveis.

Palavras-chave: Excimer laser; Miopia; Correção.

\section{REFERENCES}

1. Trokel SL, Srinivasan R, Braren B. Excimer laser of the cornea. Am J Ophthalmol 1983;96:710-5

2. Hersh PS, Brint SF, Malony RK, Durie DS, Gordon M, Michelson MA, Thompson VM, Berkeley RB, Schein OD, Steinert RF. Photorefractive keratectomy versus laser in situ keratomileusis for moderate to high myopia. A randomized prospective study. Ophthalmology 1998;105:1512-22.

3. Seiler T, Wollensak J. Results of a prospective evaluation of photorefractive keratectomy at one year after surgery. Ger J Ophthalmol 1993;2:135-42.

4. Bokobza Y, Ancel JM, Aron JJ. Résultat clinique de la photo-kératectomie réfractive. Etude préliminaire sur 57 yeux. J Fr Ophthalmol 1993;16:225-34.

5. McDonald MB, Frantz JM, Klyce SD et al. Central photorefractive keratectomy for myopia. The blind eye study. Arch Ophthalmol 1990;108:799808.

6. Holladay JT, Prager TC. Mean visual acuity.(Letter) Am J Ophthalmol 1991;111:372-4.

7. Seiler T, McDonnell. Excimer laser photorefractive keratectomy. Surv Ophthalmol 1995;40:89-118.

8. Thompson KP, Steinert RF, Stulting RD. Photorefractive keratectomy with the Summit excimer laser: the phase III U.S. results In: Salz JJ (ed): Corneal Laser Surgery. St Louis: Mosby-Yearbook, 1995; p. 57-63. 
9. Ribeiro JC, McDonald MB, Klyce SD. Photorefractive keratectomy after radial keratotomy in a patient with severe myopia. Am J Ophthalmol 1994; 118:106-8.

10. Ribeiro JC, McDonald MB, Klyce SD. Excimer laser photorefractive keratectomy resulting in more myopia postoperatively than preoperatively. Arq Bras Oftal 1998;61:181-3.
11. Halliday BL. Refractive and visual results and patient satisfaction after excimer laser photorefractive keratectomy for myopia. Br J Ophthalmol 1995;79:881-7.

12. Pallikaris IG, Siganos DS. Excimer laser in situ keratomileusis and photorefractive keratectomy for correction of high myopia. J Refract Corneal Surg 1994;10:498-510.

\title{
THIRD INTERNATIONAL SYMPOSIUM ON OPHTHALMOLOGY IN THE DEVELOPING WORLD
}

\author{
March 23-25, 2001 \\ Holiday Inn Financial District \\ San Francisco, California - USA
}

\section{Course Description:}

This two- and one-half-day symposium will bring together internationally recognized experts to discuss current issues in global blindness, including the diagnosis, prevention, and treatment of the major causes of blindness worldwide. The focus of the course will be on the Developing World but causes of blindness in the developed world will be address as well. The course is intended for ophthalmologists, general physicians, nurses, public health workers, health administrators, policy makers, and health planners.

\section{Contact Information: Karen Baranick}

Medical Conference Planners, Inc.

1251 Post Road

Scarsdale, NY 10583 USA

Tel.: (914) 722-0664

Fax: (914) $722-0465$

e-mail: medconfs@aol.com

web site: http://www.medconfs.com

Informações no Brasil: Dr. Rubens Belfort Jr.

e-mail: eyebr@webmail.epm.br 